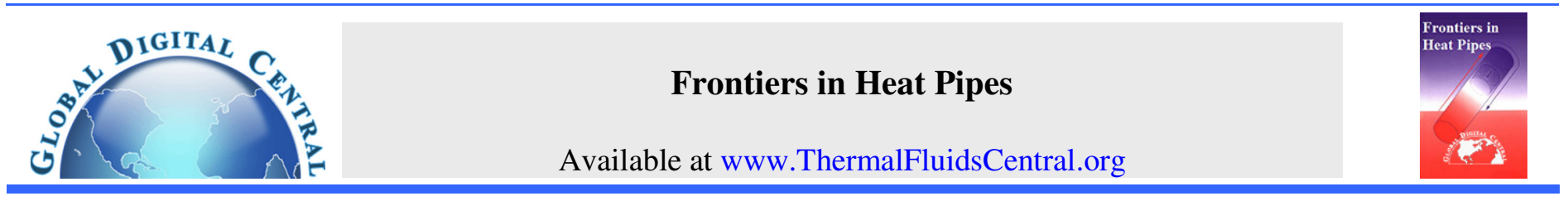

\title{
EXPERIMENTAL STUDY OF THERMAL PERFORMANCE OF A FLAT LOOP HEAT PIPE
}

\author{
Md Monir Hossain, John Kizito* \\ Mechanical Engineering Department, North Carolina A\&T State University, Greensboro, NC, 27410, USA
}

\begin{abstract}
Thermal management is an important issue for electronic cooling application. Choosing an efficient cooling technique depends on thermal performance, reliability, manufacturing cost, and prospects for minimization of packaging cost. Based on these grounds, Loop heat pipe (LHP) is a highly efficient two-phase cooling system used for passive cooling of critical components especially in satellite technology. Loop Heat Pipe uses capillary action to circulate cooling fluid. The capillary pressure developed in the pores of the wick material provides the driving force to pump the fluid. A loop heat pipe with flat evaporator has been designed and fabricated. An experimental study was performed to investigate the loop performance at different heat loads. LHP was instrumented with thermocouples to measure the temperature history at various locations of loop. Also the LHP was designed to be transparent to visualize the two phase flow phenomena. Temperature oscillations have been observed in the evaporator, vapor line and condenser during the startup of operation of the LHP. Performance of LHP has been evaluated at a certain range of evaporator heat loads. The minimum thermal resistance of LHP was $0.78{ }^{\circ} \mathrm{C} / \mathrm{W}$ for a heat load of $100 \mathrm{~W}$ while the maximum was $3.1{ }^{\circ} \mathrm{C} / \mathrm{W}$ for a heat load of $20 \mathrm{~W}$. The maximum heat transfer coefficient in the evaporator was $14114 \mathrm{~W} / \mathrm{m}^{2 \circ} \mathrm{C}$ for a heat load of $100 \mathrm{~W}$. In addition, it was found that the determination of startup and/or unstart is necessary for control and operation of LHP.

Keywords: Loop heat pipe, compensation chamber, evaporator, condenser, capillary pressure
\end{abstract}

\section{INTRODUCTION}

Heat generation in the electronic system has become a big concern with the advent of new technology. Reliability of electronic component depends on operating temperature level and the dissipated wattage. In addition, the need for cooling compact electronic system has become a big challenge for traditional cooling systems using air as coolant. Twophase cooling system like Loop Heat Pipe (LHP) has great potential to meet these future challenges especially for specific demand of aerospace technology, which requires high operational reliability and robustness (Hoang and $\mathrm{Ku}, 2002$ ). LHP can transfer heat over longer distance in any orientation than conventional heat pipe. Continuous research has been performed to improve the performance of LHP. Because of compactness of the system, LHP is successfully used in cooling of laptops and desktops (Sauciuc et al. 2005). Now the big challenge is to increase the cooling capacity while keeping the size as compact as possible (Hoang et al. 2003).

Miniaturization is very important due to compactness of electronic systems. Investigations have shown that a miniature LHP can transfer 25-30 watt heat load up to $250 \mathrm{~mm}$ distance (Pastukhov and Chernyshova, 1999). In addition, LHP is successfully used for low power management electronic cooling for spacecraft applications (Bienert and Nikitkin, 1999). Flat surface electronic unit can be easily integrated into electronic systems. For this reason, present trend of evaporator shape is either flat disc or rectangular. The working fluid can evaporate uniformly from the flat surface and thereby keeping the electronic unit temperature almost isothermal. Experiments have been performed on LHP with heat load of 40 to 80 watt with horizontal and vertical orientations using a flat disc-shaped evaporator design (Maidanik et al. 2000). In addition, an experiment was performed to understand the startup process of LHP with flat evaporator (Tu et al. 2009). The startup of LHP at low power input have shown high temperature oscillations which led to the LHP to be unstable at low as well as high heat load input ( $\mathrm{Li}$ et al. 2010). Therefore, for efficient operation of LHP, it is very important to determine the critical operating range for a given heat load input. Besides, different working fluids, wick structures and parameters have been used in flat evaporator (Liu, Z. et al. 2011). Miniature LHP with flat copper disc evaporator can transfer 70 watt and the temperature of the evaporator was below $100^{\circ} \mathrm{C}$ (Singh et al. 2008). In laptop, copper based miniature LHP was able to remove heat load of 11.5 watt from a $35 \mathrm{mmX} 35 \mathrm{~mm}$ (Moon et al. 2002). Also, copper-water miniature cylindrical LHP was used with load capacity of 130 watt for electronic cooling applications (Maydanik et al. 2005). In addition, the performance of copper wick are studied to understand the effect of heat load on the evaporator heat transfer coefficient (Maydanik and Vershinin, 2010). This paper illustrates the potential for copperwater LHP.

In the present study, a loop heat pipe is designed and developed to evaluate the performance parameters of the loop at different heat load conditions. The wick used in the loop was designed to provide required capillary pumping from copper powder. The average diameter of the selected particulate of the wick powder was $10 \mu \mathrm{m}$ resulting in $25.4 \mathrm{~mm}$ diameter and $5 \mathrm{~mm}$ thick wick. The evaporator shape was flat and designed to handle 100 watt heat load. Results of the experiment have demonstrated satisfactory operation and thermal behavior of LHPs at different applied heat load give insight into the startup behavior. This paper is organized is as follows. First, the wick fabrication process is described and then experimental setup with testing procedure is explained. Results of the experiment are analyzed and concluding remarks are made at the end of the paper.

* Corresponding author. Email: jpkizito@ncat.edu 


\section{EXPERIMENTATION}

\subsection{Fabrication process of wick}

A wick has been fabricated by sintering from fine copper powder. The copper powder was purchased from Alfa Aesar, MA, USA and the powder is mostly spherical in shape with an approximately diameter of $10 \mu \mathrm{m}$. Fig 1 shows a scanning electron microscope (SEM) image used to confirm the size and shape of the powder. The fine powder diameter was selected to meet the requirement of high capillary pressure to overcome the system pressure drop. Preliminary calculation shows that a copper wick composed of 8-10 micron mean pore diameter and $40 \%$ porous volume can offer sufficient capillary pumping capability to circulate working fluid in the loop at different heat loads.

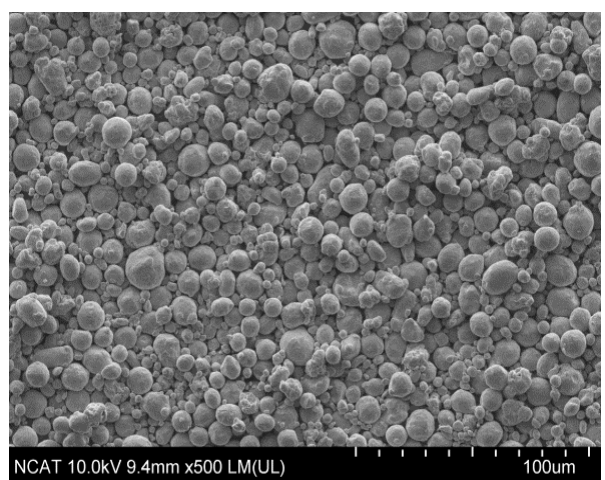

Fig. 1 SEM image of spherical copper powder

The wick thickness was determined to be $5 \mathrm{~mm}$. In addition, the wick structure also functions as a thermal and hydraulic link between compensation chamber and evaporator. The wick was prepared in stainless steel mold by cold pressing. After cold pressing the powder of the wick was loaded in a tube furnace for sintering. A protective atmosphere was maintained during the sintering process to avoid the oxidation of the samples. Prior to the sintering process, pure nitrogen gas was allowed to flow for 1.5 hours to purge the furnace tube. During the purging process, oxygen was allowed to diffuse out of the pores of the wick. The forming gas consists of $4 \%$ hydrogen and $96 \%$ nitrogen (Dominguez Espinosa et al. 2012). The forming gas was allowed to flow throughout the sintering process.

Fig. 2 shows a temperature-time plot of the sintering process. The heating rate of $600{ }^{\circ} \mathrm{C} / \mathrm{h}$ was maintained to reach the peak sintering temperature. The peak sintering temperature was $450{ }^{\circ} \mathrm{C}$. The furnace was held at the peak sintering temperature for 30 minutes. At the end of sintering process, the wick was cooled inside the furnace. After the temperature reached below $200{ }^{\circ} \mathrm{C}$, the application of forming gas was discontinued and only pure nitrogen was applied. The flow of nitrogen was stopped once the wick reached the room temperature.

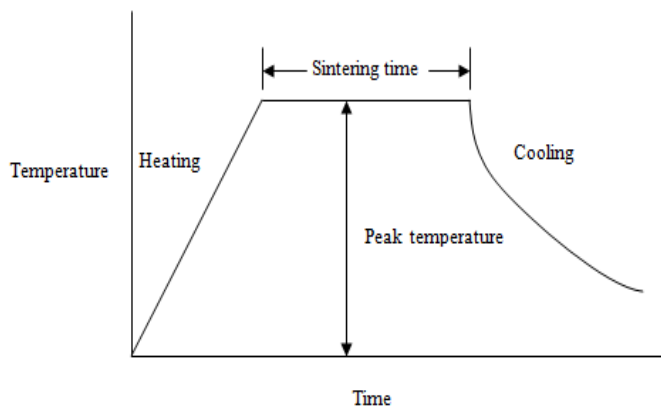

Fig. 2 Time-temperature plot of the sintering process.
Figure 3 shows the sintered copper wick together with its SEM image. The fig shows that the particles bonded together by sintering process. The wick powder becomes a single piece. For proper material properties, the wick should be sintered at $450{ }^{\circ} \mathrm{C}$ or above. The porosity of sample is $40 \%$ which is calculated from the equation given below

Porosity $(\%)=1-\frac{\rho_{\text {sample }}}{\rho_{\text {material }}}$

where $\rho_{\text {sample }}$ is the density of the wick and $\rho_{\text {material }}$ is the density of the base copper powder. Density of the porous wick was calculated by dividing the mass of the wick by the volume of the wick. A digital balance measured the mass of the wick. The uncertainty in the measurement was $1 \%$.

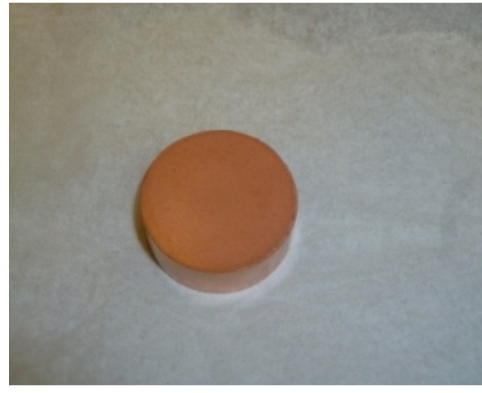

(a)

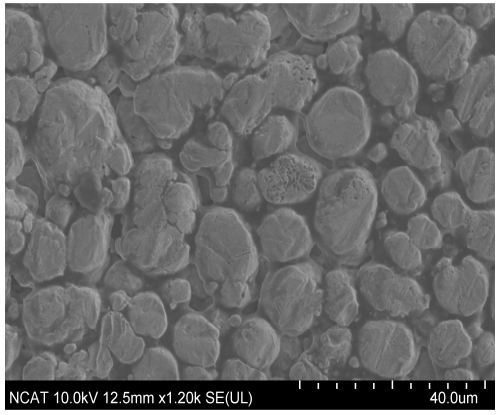

(b)

Fig. 3 a) Sintered copper wick (b) SEM image of sintered copper wick

\subsection{Experimental set-up}

The capillary pressure gain in the wick must be balanced by the pressure loss in each component of the loop for steady-state operating condition. The pressure drop can be written as:

$\Delta \mathrm{P}_{\text {cap max }} \geq \Delta \mathrm{P}_{\text {wick }}+\Delta \mathrm{P}_{\text {cond }}+\Delta \mathrm{P}_{\text {vapor line }}+\Delta \mathrm{P}_{\text {liquid line }}$

Maximum operating pressure is obtained from the evaporating menisci formed at the pore of the wick. Capillary limit of the loop depends on the wick design, surface tension of working fluid, contact angle between the liquid and solid, and pore radius of the wick. Capillary limit of the loop can be expressed by Young-Laplace equation as:

$$
\Delta \mathrm{P}_{\text {cap max }}=\frac{2 \sigma \cos \theta}{r}
$$

where $\sigma$ is the surface tension of working fluid, $\theta$ is the contact angle between the liquid and solid, and $\mathrm{r}$ is the pore radius of the wick.

In the present study, water is used as working liquid. The reason for using water as working fluid is the high surface tension which has a capacity to increase the capillary pressure. Besides for proper functioning of the loop, wick should be compatible with working fluid. 
Water was found to have a good compatibility with copper wick. The schematic of LHP is shown in Fig. 4.

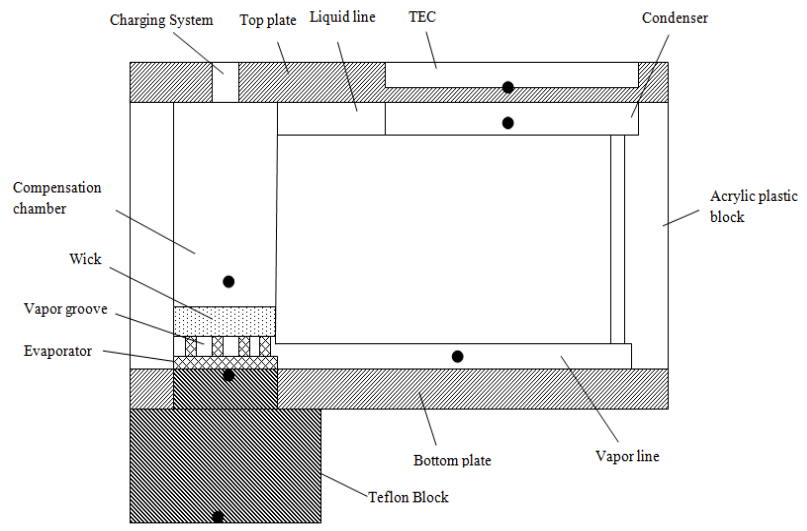

Fig. 4 Schematic of LHP (black circle indicates location of thermocouples)

The experimental setup is shown in Fig. 5. Most of the LHP are made from either copper or stainless steel or from other metallic component. These models cannot provide any comprehensive picture of the system. It is very important to investigate the behavior of the fluid inside the evaporator and in condenser where the phase changes take place. In this experiment, the main structure of the loop heat pipe is fabricated inside an acrylic plastic block which is shown in Fig. 6. Transparent acrylic plastic was used for visualization of operation in different components of LHP. The maximum temperature, block can withstand was $140^{\circ} \mathrm{C}$. The dimension of the plastic block $(\mathrm{LxWxH})$ is $143 \times 80 \times 50 \mathrm{~mm}$. The diameter of the compensation chamber was $23 \mathrm{~mm}$ and height was $38.5 \mathrm{~mm}$. The evaporator section, which holds the wick, was $27 \mathrm{~mm}$ diameter and the height of the chamber was $12.5 \mathrm{~mm}$. The volume of the compensation chamber was made equal to the total internal volume of the other component of loop to accommodate displaced liquid.

The rectangular vapor channel was $5 \mathrm{~mm}$ width, $5 \mathrm{~mm}$ depth and 70 $\mathrm{mm}$ long. The channel was connected to a $3 \mathrm{~mm}$ diameter and $40 \mathrm{~mm}$ length vapor line to the condenser. A liquid rectangular channel was used to attach the compensation chamber with the condenser. The dimension of the liquid channel was $5 \mathrm{~mm}$ width, $5 \mathrm{~mm}$ depth and $30 \mathrm{~mm}$ length. Two-aluminum plates were used to cover the top and bottom of the plastic mold. The thicknesses of the plates were $6 \mathrm{~mm}$. The length and width of the both the plates were $143 \mathrm{~mm}$ and $80 \mathrm{~mm}$ respectively.

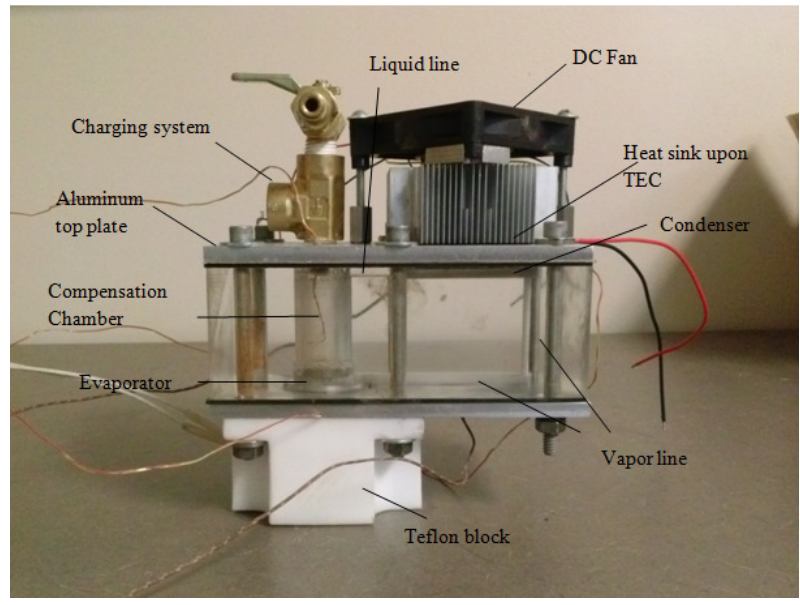

Fig. 5 Experimental setup of LHP

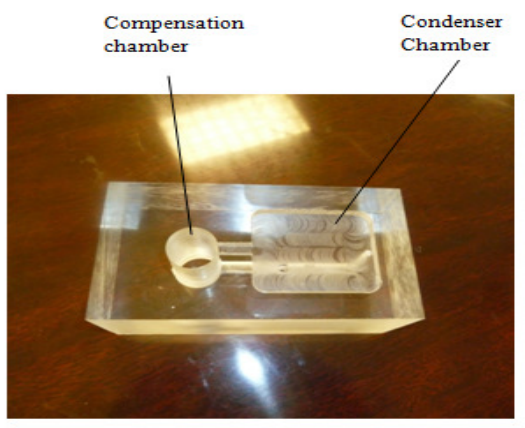

(a)

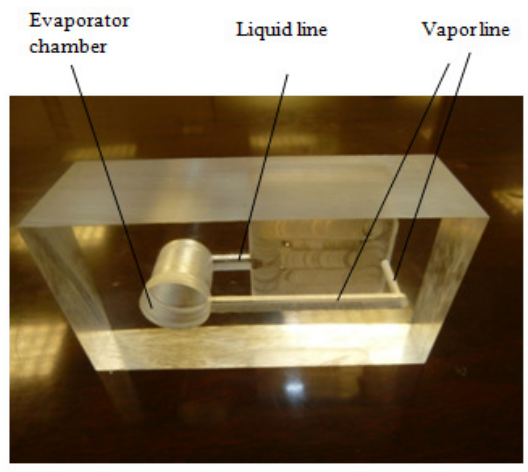

(b)

Fig. 6 Main structure of LHP: (a) top view (b) bottom view

Vapor grooves were used under the wick to remove the generated vapor form the evaporator section to vapor line. Vapor groove were machined from aluminum because aluminum has high heat conductivity and it is able to conduct the heat from heat source to the wick. Vapor removal channels are small grooves with rectangular cross-section of 4 $\mathrm{mm}$ depth and $1 \mathrm{~mm}$ width. Fig. 7 shows the vapor removal channel used in the evaporator. The grooves have two main functions. First, the fins of grooves work as heat conductor between heat source and the wick and secondly the channels are designed to remove the vapor to the vapor line.

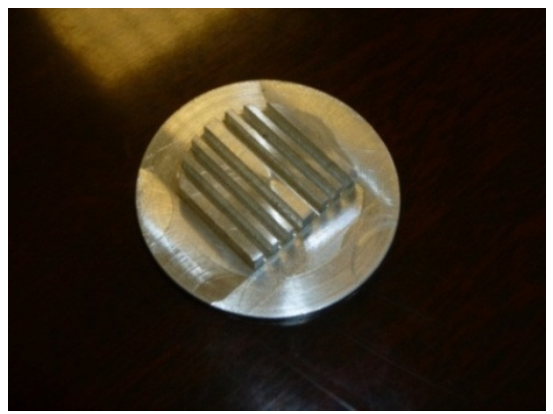

Fig. 7 Aluminum vapor groove in evaporator

Heat in the evaporator is applied through a heater block assembly. The heater block is made of copper material because of its high thermal conductivity. The diameter of cylindrical heater block is $31.75 \mathrm{~mm}$ and the length is $38 \mathrm{~mm}$. A $6.35 \mathrm{~mm}$ of hole was made in the heater block to accommodate the heater cartridge. A high-density150-watt cartridge heater was inserted into the heater block. A programmable power supply was connected to the cartridge heater to simulate the heat source. When considering a heat load, a proper heater-block fit is an important issue for performance and life expectancy of the heater. The recommended fit for the heater was $0.25 \mathrm{~mm}$. To minimize the heat loss from the heater block 
to the surrounding environment, a Teflon ${ }^{\circledR}$ PTFE resins block as shown in Fig. 8 was used for insulation. The insulating block ensures heat transmittance only in evaporator direction. The insulating material must be chemical resistance, inert and can withstand high temperatures (up to $260^{\circ} \mathrm{C}$ ). Two high temperature gaskets were used for insulation and to prevent the any leakage from LHP to the surrounding environment. Paste was also used around the circumference of the wick to prevent any internal leaks of vapor back to the compensation chamber and to minimize heat conduction from the evaporator side walls to the wick structure. The design ensures proper surface contact between the wick and vapor channel to maximize heat conductance.

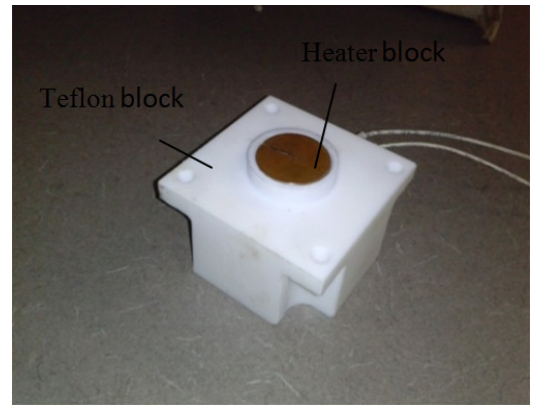

Fig. 8 PTFF Teflon block for heater block insulation

Normally the condensation process is performed by liquid coolant or by air circulation. In the present design, a rectangular chamber of 50 $\mathrm{mm}$ length and $50 \mathrm{~mm}$ width and $5 \mathrm{~mm}$ depth was designed on the top of the acrylic mold to condense the vapor. A Thermo Electric Cooler (TEC) was used to enhance the condensation process. TEC is placed inside the groove machined at the top aluminum plate. The power to the cooling system can be measured more accurately when using TEC compared to conventional air or liquid cooling systems. The cold face of the TEC will provide the necessary cooling and the heat will be remove using interface between TEC and a cooling fan and aluminum sink. Contact between the plate and the TEC was ensured by using a high conductive thermal silicon paste.

Non-condensable gases (NCG) can reduce effectiveness and hinder the operation of LHP. Mostly NCG are generated reduce to effectiveness of the LHP. NCG are due to dissolved gases in the working fluid. Preprocessing is essential for minimizing the effect of NCG. De-ionized water was used to clean the components of LHP. A special charging system (Fig. 9) has been used for charging the working liquid in the loop. A three-way valve was attached upon the top plate of LHP. One port of three-way valve was connected to a vacuum pump and the other port is connected to the liquid charging cylinder. The third port was connected to the compensation chamber of the loop. Before charging the liquid, vacuum pump is used to evacuate air (NCG) from the loop. To avoid NCG formation cooled deionizer water was charged into the loop gradually. The amount of water charged inside the loop heat pipe was $50 \%$ or higher of the volume of compensation chamber.

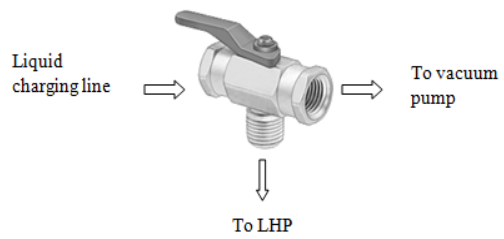

\subsection{Testing procedure}

The thermal performance of LHP was tested using copper block embedded with one cartridge heater. A power supply (Agilent Technologies, 5301 Stevens Creek Blvd, CA 95051, USA) was used to provide power to the cartridge heater. At each voltage, a corresponding current was recorded and the power output was determined. The temperature was measured at different points of LHP by using K-Type thermocouples shown in Fig.4. Six thermocouples were used to read the temperature history at the different locations of the system. These thermocouples are directly connected to IOtech 6000 series DAQ data acquisition system. The data acquisition system collected the data after every 0.5 second lapse and displayed the data on the computer connected to acquisition system. Error in temperature measurement by $\mathrm{K}$ type thermocouples was $\pm 0.1^{\circ} \mathrm{C}$ and uncertainty in the power measurement was \pm 0.2 percentage.

\section{RESULT AND DISCUSSIONS}

Figure 10 shows the startup process for 30 -watt heat input power. The heat load was relatively low. At low heat load, the heat load applied to the evaporator causes vaporization of working fluid in the wick. The capillary pressure developed in the wick circulates the working fluid in the loop. This pressure also displaces excess water out of vapor groove and vapor line. The figure shows temperature oscillation in evaporator, compensation chamber and vapor line around 1000 second lapse. Temperature oscillation is observed especially in compensation chamber and vapor line temperature. The temperature oscillation for compensation chamber starts when the temperature is about $85^{\circ} \mathrm{C}$. The amplitude of oscillation was about $5^{\circ} \mathrm{C}$ in compensation chamber. The unsteady behavior in compensation chamber continues until the loop operation becomes steady as will be shown later for high load input. Also it was observed that, during the startup process, the vapor line is flooded with water. The incoming vapor drives out the liquid from vapor line. The vapor generation and collapsing of bubbles during the startup caused high oscillation in vapor line temperature until the vapor line was free of liquid. The temperatures of both TEC and the condenser were below $20^{\circ} \mathrm{C}$ and variations in temperature are small during operation. At low heat loads, vapor flow rate was small. The temperature of the compensation chamber was determined by a balance between in and out flow to the compensation chamber in addition to the parasitic heat flow from evaporator to the compensation chamber. Heat inflow and liquid displaced to the compensation chamber increase with heat load until the compensation chamber and evaporator temperature became stable.

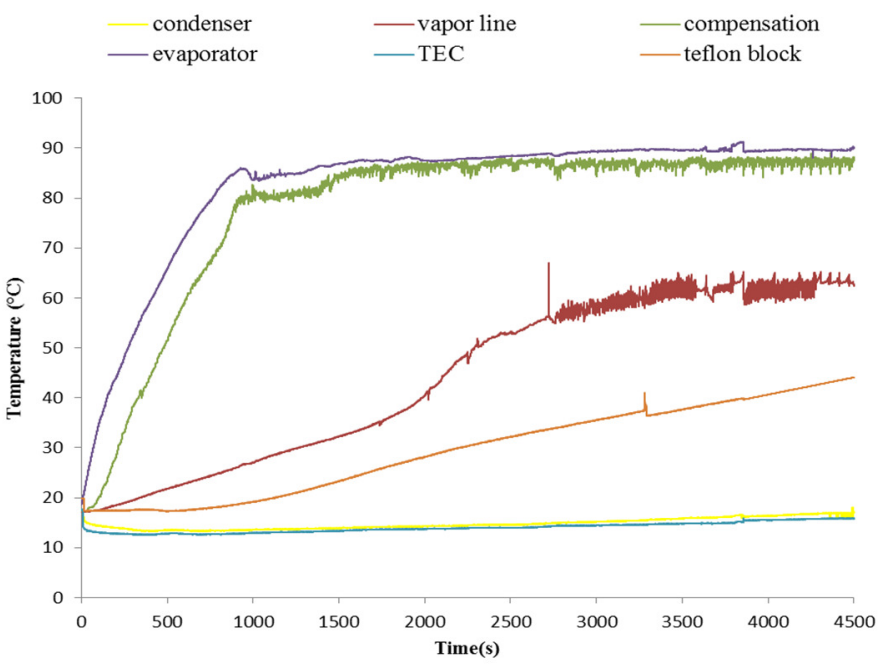

Fig. 10 LHP startup process with 30 watt heating power

Fig. 9 Charging system of LHP 
Figure 11 shows startup process for 70 watt heat load. Startup process is faster and more stable than the relatively low heat load startup process. Evaporation process becomes more stable at relatively higher heat load. Initially, the evaporator temperature rises very quickly and it becomes stable around $100^{\circ} \mathrm{C}$. The temperature of the compensation chamber became stable around $80^{\circ} \mathrm{C}$ for these conditions. The vapor line temperature rise was almost three times quicker than 30 watt case. There was also an increase in TEC and condenser temperature. The increase can be attributed to the increase in vapor generation.

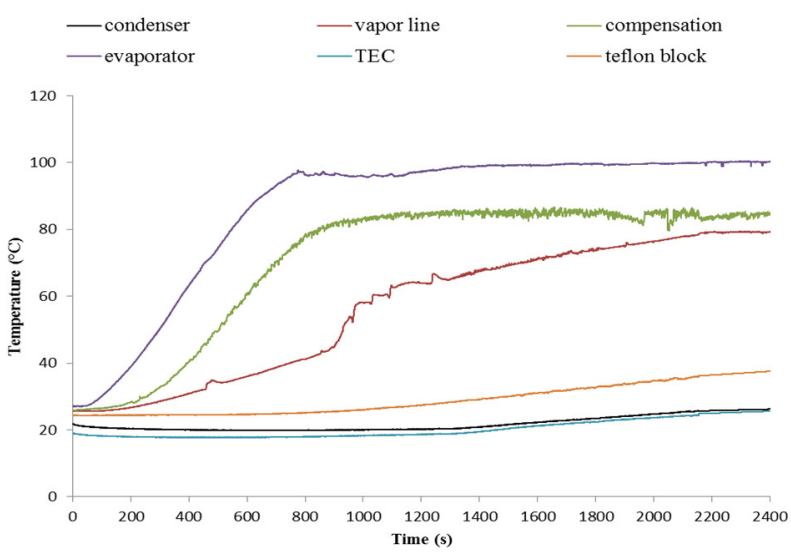

Fig. 11 LHP startup process with 70 watt heating power

Figure 12 shows the temperature history for the startup when 100 watt heat load input was used. In this case, LHP started very quickly. The evaporator temperature rises very quickly and bubble generation becomes more faster than previous case. The temperature at the beginning of evaporation exhibits high oscillation which eventually stabilized after an initial period. At the beginning of the evaporation process, the meniscuses in the pores of the evaporator wick are unstable which causes high temperature oscillation in the system. After couple of minutes the meniscus becomes stable and the temperature rises more steadily. Vapor line temperature is low at this initial stage. But rapid temperature rise can be observed after 700 seconds. The compensation chamber temperature rises with little oscillation and becomes stable at $70^{\circ} \mathrm{C}$. The TEC and condenser temperature remains almost same. The figure shows that fast vapor generation and stable operation mode can be achieved at relatively high heat load with negligible fluctuations in the temperature.

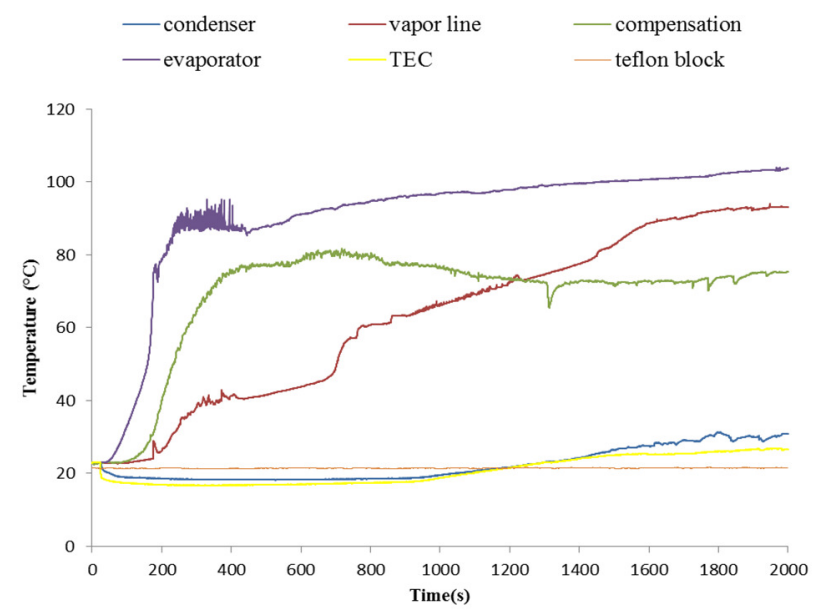

Fig. 12 LHP startup process with 100 watt heating power
Figure 13 shows a plot of heat load and averaged evaporator temperature after the evaporator temperature becomes stable. The plot indicates monotonic temperature trend with the changing heat load. The evaporator temperature increases with increase of heat load which indicates constant conductance mode in loop operation after the evaporator temperature reaches the stable condition.

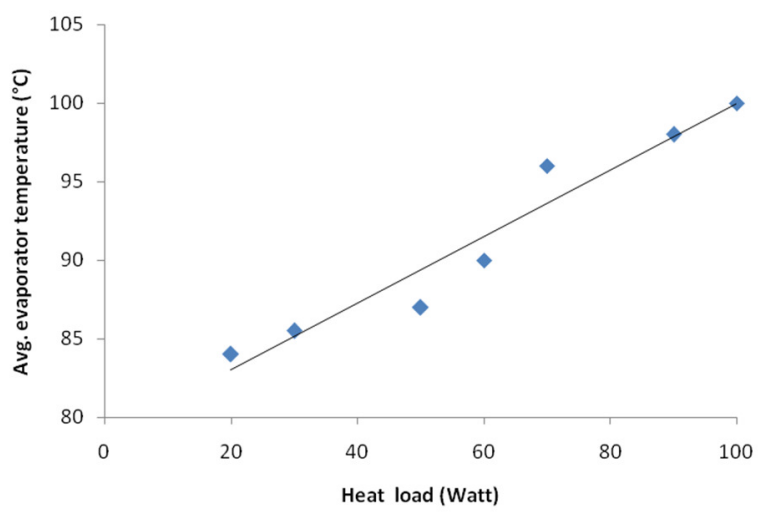

Fig. 13 Average evaporator temperature vs. heat load

The total thermal resistance of the LHP at different load is shown in Fig. 14. Total thermal resistance is an important parameter for determining the performance of a loop heat pipe. Total thermal resistance can be defined as

$$
R_{t h}=\frac{T_{e}-T_{C}}{Q}
$$

where $T_{e}$ is the temperature at the evaporator; $T_{c}$ is the temperature at the condenser and $\mathrm{Q}$ is the applied load at the evaporator. The thermal resistance provides the idea of resistance of the system to heat flow. Thermal resistance affected by the heat transfer to the condenser and heat leakage to the compensation chamber. Heat leakage to the compensation chamber is high at the low heat load. Most of the applied load is transmitted to compensation chamber. As the heat load increases, the total thermal resistance decreases because the system now transmits more heat to the evaporator and the heat load leakage to the compensation chamber is comparatively low. Vapor generation increases with the increase in heat load. As a result, the fluid circulation from condenser to compensation chamber increases and balances the heat leakage from evaporator to compensation chamber. The maximum and minimum value of total thermal resistance of the loop was $3.1^{\circ} \mathrm{C} / \mathrm{W}$ and $0.78^{\circ} \mathrm{C} / \mathrm{W}$ respectively. Therefore, these results show that the smaller the thermal resistance, the better the performance of the LHP.

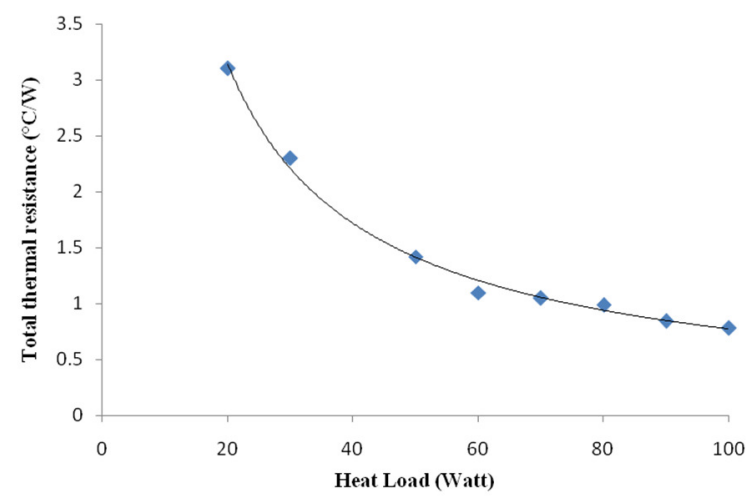

Fig. 14 Total thermal resistance vs. heat load 
Effectiveness of the thermal system can be determined from heat transfer coefficient. The heat transfer coefficient of the loop can be calculated as follows

$$
\mathrm{h}=\frac{\mathrm{Q}}{\mathrm{A}_{\mathrm{e}}\left(\mathrm{T}_{\mathrm{e}}-\mathrm{T}_{\mathrm{V}}\right)}
$$

where $\mathrm{Q}$ is the applied load on the evaporator, $\mathrm{A}_{\mathrm{e}}$ active heated area of the evaporator, $\mathrm{T}_{\mathrm{e}}$ is the temperature of the evaporator and $\mathrm{T}_{\mathrm{V}}$ is the temperature of the vapor outlet. Fig. 15 shows heat transfer coefficient at different heat loads. The figure shows a monotonically increase in heat transfer coefficient with respect to the heat load. Maximum value of heat transfer coefficient in the evaporator is $14.114 \mathrm{~kW} / \mathrm{m}^{2} .{ }^{\circ} \mathrm{C}$ for 100 Watt heat load and the minimum value is $1.08 \mathrm{~kW} / \mathrm{m}^{2} .{ }^{\circ} \mathrm{C}$ for 20 watt. The figure shows that high values of the heat transfer coefficient can be achieved at relatively high heat loads and at low thermal resistance.

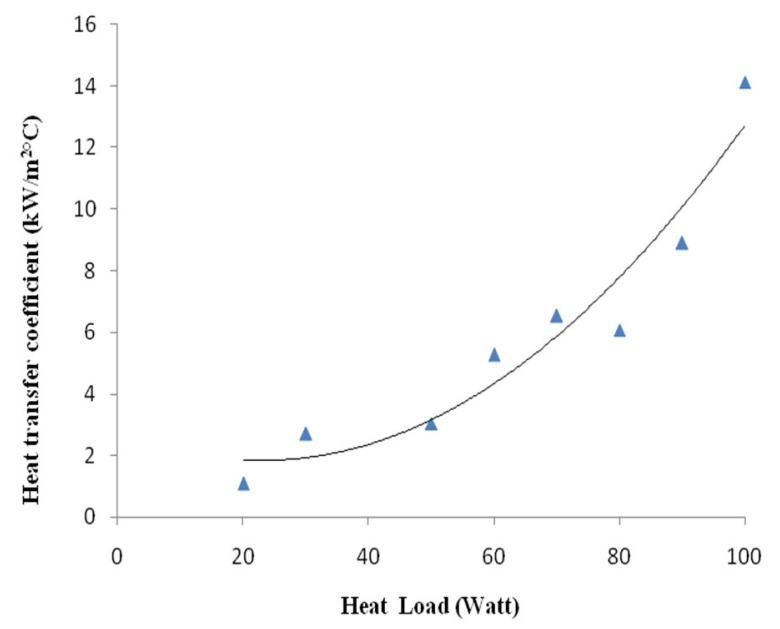

Fig. 15 Heat transfer coefficient vs. heat load

\section{CONCLUSIONS}

A flat loop heat pipe is fabricated with a copper wick of $25.4 \mathrm{~mm}$ diameter and $5 \mathrm{~mm}$ thickness. The sintering process as well as the dimension of has been considered carefully to achieve the sufficient capillary pressure to run the system. The LHP has dissipated maximum heat load of $100 \mathrm{~W}$. The TEC with heat sink and DC fan has been used to promote the condensation process. The shape of the evaporator is flat (a low aspect ratio) which reduces thermal resistance between the heat source and the evaporator.

The minimum thermal resistance of LHP is $0.78{ }^{\circ} \mathrm{C} / \mathrm{W}$ for a heat load of $100 \mathrm{~W}$ while the maximum is $3.1^{\circ} \mathrm{C} / \mathrm{W}$ for heat load a for $20 \mathrm{~W}$. Maximum heat transfer coefficient in the evaporator is $14114 \mathrm{~W} / \mathrm{m}^{2 \circ} \mathrm{C}$ for a heat load of $100 \mathrm{~W}$. Temperature oscillation were observed in evaporator, compensation chamber and vapor line temperature during the startup operation. Especially, the vapor generation and collapsing of bubbles during the startup caused high oscillation in vapor line temperature. The temperature becomes stable after the initial startup process. Fast vapor generation and stable operation mode has been achieved for relatively high heat load. The device has performed satisfactorily for different applied heat loads.

\section{ACKNOWLEDGMENTS}

This research was funded by the Department of Defense through WrightPatterson Air Force Research Laboratory Dayton, Ohio via a sub contract from United Technologies. The authors express their sincere appreciation for all of the support provided.

\section{NOMENCLATURE}

$\begin{array}{ll}P & \text { pressure }\left(\mathrm{N} / \mathrm{m}^{2}\right) \\ R & \text { thermal resistance }\left({ }^{\circ} \mathrm{C} / W\right) \\ T & \text { temperature }\left({ }^{\circ} \mathrm{C}\right) \\ Q & \text { heat load }(\mathrm{W}) \\ h & \text { heat transfer coefficient }\left(\mathrm{KW} / \mathrm{m}^{2 \circ} \mathrm{C}\right) \\ A & \text { area }\left(\mathrm{m}^{2}\right) \\ r & \text { pore radius }(\mathrm{m})\end{array}$

$\begin{array}{ll}\text { Greek Symbols } \\ \sigma & \text { surface tension }(\mathrm{N} / \mathrm{m}) \\ \rho & \text { density }\left(\mathrm{kg} / \mathrm{m}^{3}\right) \\ \theta & \text { contact angle }(\mathrm{rad})\end{array}$

Subscripts

evaporator

c condenser

$v \quad$ vapor

cap max maximum capillary pressure

\section{REFERENCES}

Bienert W. B., K. W. J., Nikitkin M. N., 1999, "Thermal Control with Low Power Miniature Loop Heat Pipes," 29th Int. Conf. Environ. Syst., Denver, CO.

Dominguez Espinosa, F. A., Peters, T. B. and Brisson, J. G., 2012, "Effect of Fabrication Parameters on the Thermophysical Properties of Sintered Wicks for Heat Pipe Applications," International Journal of Heat and Mass Transfer, 55(25-26), 7471-7486. http://dx.doi.org/10.1016/j.ijheatmasstransfer.2012.07.037

Hoang, T. T. and $\mathrm{Ku}$, J., 2002, "Advanced Loop Heat Pipes for Spacecraft Thermal Control," 8th AIAA/ASME Joint Thermophysics and Heat Transfer Conference, St. Louis, Missouri, 24-26.

Hoang, T. T., O'Connell, T. A., Ku, J., Butler, C. D. and Swanson, T. D., 2003, "Miniature Loop Heat Pipes for Electronic Cooling," ASME 2003 International Electronic Packaging Technical Conference and Exhibition,American Society of Mechanical Engineers, 517-525.

Li, J., Wang, D. and Peterson, G., 2010, "Experimental Studies on a High Performance Compact Loop Heat Pipe with a Square Flat Evaporator," Applied Thermal Engineering, 30(6), 741-752. http://dx.doi.org/10.1016/j.applthermaleng.2009.12.004

Liu, Z., Gai, D., Li, H., Liu, W., Yang, J. and Liu, M., 2011, "Investigation of Impact of Different Working Fluids on the Operational Characteristics of Miniature LHP with Flat Evaporator," Applied Thermal Engineering, 31(16), 3387-3392.

http://dx.doi.org/10.1016/j.applthermaleng.2011.06.023

Li J, Lin F, Wang D, Tian W, 2013, "A Loop-Heat-Pipe Heat Sink with Parallel Condensers for High-Power Integrated LED Chips," Applied Thermal Engineering 56: 18-26

Maydanik, Y. F. and Vershinin, S., 2010, "Development and Investigation of Copper-Water Loop Heat Pipes with High Operating Characteristics," Heat Pipe Science and Technology, An International Journal, 1(2). 
Maydanik, Y. F., Vershinin, S. V., Korukov, M. A. and Ochterbeck, J. M., 2005, "Miniature Loop Heat Pipes-a Promising Means for Cooling Electronics," Components and Packaging Technologies, IEEE Transactions on, 28(2), 290-296. http://dx.doi.org/10.1109/TCAPT.2005.848487

Moon, S. H., Hwang, G., Yun, H. G., Choy, T. G. and Kang, Y. I., 2002, "Improving Thermal Performance of Miniature Heat Pipe for Notebook PC Cooling," Microelectronics Reliability, 42(1), 135-140. http://dx.doi.org/10.1016/S0026-2714(01)00226-8

Maidanik,Y. F.,Vershinin, S.and Chernysheva, M., 2000, "Development and Tests of Miniature Loop Heat Pipe with a Flat Evaporator,"SAE Technical Paper.

http://dx.doi.org/10.4271/2000-01-2491

Pastukhov, V. G., Maidanik, Y. F., and Chernyshova, M. A., 1999, "Development and Investigation of Miniature Loop Heat Pipes," 29th Int. Conf. Environ. Syst., Denver, CO.
Sauciuc, I., Prasher, R., Chang, J. Y., Erturk, H., Chrysler, G., Chiu, C. P. and Mahajan, R., 2005,"Thermal Performance and Key Challenges for Future CPU Cooling Technologies," ASME Conference Proceedings, 42002, 353-364.

Singh, R., Akbarzadeh, A. and Mochizuki, M., 2008, "Operational Characteristics of a Miniature Loop Heat Pipe with Flat Evaporator," International Journal of Thermal Sciences, 47(11), 1504-1515. http://dx.doi.org/10.1016/j.ijthermalsci.2007.12.013

Singh R, Akbarzadeh A, Dixon C, Mochizuki M, 2009, "Theoretical Modelling of Miniature Loop Heat Pipe," Heat and mass transfer 46: 209-224

Tu, Z., Liu, Z., Liu, C., Gai, D., Wan, Z. and Liu, W., 2009, "Heat and Mass Transfer in a Flat Disc-shaped Evaporator of a Miniature Loop Heat Pipe," Proceedings of the Institution of Mechanical Engineers, Part G: Journal of Aerospace Engineering, 223(6), 609-618. 